\title{
ADUBAÇÃO VERDE EM POMAR CÍTRICO ${ }^{1}$
}

\author{
CARLOS RENATO ALVES RAGOZO², SARITA LEONEL ${ }^{3}$, ADALBERTO JOSÉ CROCCI ${ }^{4}$
}

\begin{abstract}
RESUMO - A utilização de adubos verdes na citricultura ainda é pouco estudada, embora possa trazer benefícios ao citricultor, do ponto de vista econômico e de preservação dos recursos ambientais. O trabalho teve como objetivo avaliar a eficiência da utilização de adubos verdes em um pomar de laranjeira 'Pêra' enxertada em limoeiro 'Cravo'. Foram empregados quatro tratamentos correspondentes aos adubos verdes avaliados: feijão-de-porco (Canavalia ensiformis)), labe-labe (Dolichus lablab), feijão-guandu-anão (Cajanus cajan) e braquiária (Brachiaria brizantha como testemunha). Os adubos verdes foram semeados nas entrelinhas da cultura e posteriormente foram roçados e direcionados para a linha na ocasião do pleno florescimento, 120 dias após a semeadura dos mesmos. O delineamento experimental foi em blocos ao acaso, com quatro tratamentos, seis repetições e duas plantas úteis para as avaliações. As características avaliadas foram: peso médio dos frutos, número de frutos por caixa de colheita (40,8 kg), produtividade, teores de matéria seca e de macro e micronutrientes contidos nos tratamentos, bem como rendimento de suco e "ratio". Os resultados obtidos evidenciaram não haver diferença estatística entre os tratamentos para as características de produtividade das plantas e qualidade dos frutos. O feijão-guandu-anão apresentou o maior teor de matéria seca no primeiro ano de experimentação, diferindo estatisticamente dos demais tratamentos. No segundo ano, diferiu estatisticamente do feijão-de-porco e do labe-labe, produzindo maior quantidade de biomassa.
\end{abstract}

Termos para indexação: Citrus sinensis, Citrus limonia, produção, crescimento, cobertura vegetal, qualidade de frutos.

\section{GREEN MANURE IN CITRUS ORCHARD}

ABSTRACT - The green manures utilization in citrus orchards is little studied yet, therefore can enhance the yield and preserve the nature. The purpose of the experiment was to evaluate the efficiency of the use of green manures on an orchard planted with 'Pera' sweet orange, situated Botucatu/SP. Four different treatments were applied: jack bean (Canavalia ensiformis), lab-lab (Dolichus lablab), dwarf guandu (Cajanus cajan) and brachiaria (Brachiaria brizantha) as control. They were sown, then grubbleb and moved directed next to the line plants by the occasion of full flowering. The experimental design was a randomized blocks with four treatments, six replications, and two useful plants per plot. Characteristics evaluated were: average fruits weight, number of fruits per boxes $(40,8 \mathrm{Kg})$, productivity, percentage of dry matter and the contents of macro and micronutrients in the treatments. Also, it was evaluated the juice content and ratio. The results obtained showed that there was no statistical significant differences among green manures in orange yield and the fruits quality. Dwarf guandu showed a higher dry matter content in the first year of experimentation, differing from the other treatments. In the second year, it differed from jack bean and lab-lab, producing a higher quantity of biomass.

Index terms: Citrus sinensis, Citrus limonia, yield, growth, green manure, fruits quality.

\section{INTRODUÇÃo}

O maior desafio do citricultor é obter um produto que atenda ao mercado consumidor, seja de frutas frescas, seja para a indústria, a custos baixos, alcançando uma renda compatível com o investimento do empreendimento e com o custeio anual que a cultura demanda.

A citricultura paulista está localizada em regiões de solos de textura média a arenosa, conforme um estudo de Demattê \& Vitti (1992), onde $65 \%$ das áreas estudadas apresentaram solos de textura média com teor de argila na superfície de $15 \%$ a $35 \% ; 30 \%$ com solos de textura arenosa (teor de argila até $15 \%$ ) e, praticamente, $5 \%$ encontravamse em solos argilosos, o que obriga o produtor a lançar mão de insumos externos para viabilizar a atividade, elevando os custos de produção da fruta cítrica. De acordo com Melarato (1998), a maior parte dos solos tropicais apresenta características semelhantes, principalmente nas áreas onde a citricultura se expandiu nos últimos anos, dentre as quais pode ser destacado o alto grau de intemperização, a acidez elevada, a grande quantidade de alumínio, a baixa capacidade de retenção de cátions e os baixos teores de bases trocáveis.

Dentro do contexto de buscar redução dos custos de produção, a utilização da adubação verde cresce no Brasil, apoiada por trabalhos científicos em citros, que mostram os efeitos benéficos desta prática milenar na agricultura (Silva et al., 1999), determinando menos agressões ao meio ambiente (Ambrosano et al., 2000).

Segundo estudos científicos e evidências práticas, os adubos verdes desempenham ações em diferentes aspectos da fertilidade do solo, tais como: proteção do solo contra os impactos das chuvas e também da incidência direta dos raios solares; rompimento de camadas adensadas e compactadas ao longo do tempo; aumento do teor de matéria orgânica do solo; incremento da capacidade de infiltração e retenção de água no solo; diminuição da toxicidade do Al e Mn devido ao aumento de complexificação e elevação do $\mathrm{pH}$; promoção do resgate e da reciclagem de nutrientes de fácil lixiviação; extração e mobilização de nutrientes das camadas mais profundas do solo e subsolo, tais como $\mathrm{Ca}, \mathrm{Mg}, \mathrm{K}, \mathrm{P}$ e micronutrientes; extração do fósforo fixado; fixação do N atmosférico de maneira simbiótica pelas leguminosas; inibição da germinação e do crescimento de plantas invasoras, seja por efeitos alelopáticos, seja pela simples competição por luz (Von Osterroht, 2002).

O presente trabalho teve como objetivos avaliar possíveis incrementos na produção de plantas cítricas e diferenças em relação à qualidade dos frutos, quando introduzida a técnica da adubação verde em um pomar de laranjeira 'Pêra' [Citrus sinensis (L.) Osbeck] e, também, detectar qual o melhor adubo verde a ser empregado.

\section{MATERIAL E MÉTODOS}

O experimento foi desenvolvido na fazenda Três Irmãos, município de Botucatu-SP. O clima da região é do tipo Cwa, segundo a classificação climática de Köeppen (Mello et al., 1994). A precipitação pluviométrica média anual é de $1.445 \mathrm{~mm}$, apresentando temperatura média anual de $21^{\circ} \mathrm{C}$ e evapotranspiração de $700 \mathrm{~mm}$. A denominação do solo do local é Neossolo quartzarênico, de acordo com critérios da Embrapa (1999).

A cultivar copa estudada foi a laranjeira 'Pêra' enxertada em limoeiro 'Cravo' (C. limonia Osbeck). O pomar comercial está plantado no espaçamento de $7 \mathrm{~m}$ entre linhas e $4 \mathrm{~m}$ entre plantas e vem recebendo

\footnotetext{
${ }^{1}$ (Trabalho 169/2005). Recebido: 17/10/2005. Aceito para publicação: 08/03/2006.

${ }^{2}$ Prof $^{a}$. Dr ${ }^{a}$. Universidade Estadual Paulista. Faculdade de Ciências Agronômicas. Departamento de Produção Vegetal. Cx Postal 237. CEP 18603.970. BotucatuSP. E-mail: sarinel@fca.unesp.br.

${ }^{3}$ Eng $^{\mathrm{o}}$. Ag ${ }^{\mathrm{o}}$. Msc. Doutorando em Horticultura. UNESP/FCA/Botucatu. E-mail: jrragozo@btu.flash.tv.br.

${ }^{4}$ Prof $^{\circ}$. Dr ${ }^{\circ}$. Universidade Estadual Paulista. Instituto de Biociências. Departamento de Bioestatística. ajcrocci@ibb.unesp.br.
} 
TABELA 1 - Médias relativas ao número de frutos por caixa de 40,8 kg, de pomar de laranjeira 'Pêra' [Citrus sinensis (L.) Osb.] submetido a diferentes adubos verdes. Botucatu-SP, 2005.

\begin{tabular}{|c|c|c|c|c|}
\hline & \multicolumn{4}{|c|}{ Tratamentos } \\
\hline Época & Feijão-de-porco & Guandu-anão & Labe-labe & Braquiária \\
\hline $20-09-2003$ & $204,2 \mathrm{Aa}$ & $210,0 \mathrm{Aa}$ & $204,0 \mathrm{Aa}$ & $212,3 \mathrm{Aa}$ \\
\hline $28-10-2003$ & $263,0 \mathrm{Ab}$ & $245,0 \mathrm{Ab}$ & $252,2 \mathrm{Ab}$ & $246,2 \mathrm{Ab}$ \\
\hline $1^{\circ}-11-2004$ & $230,8 \mathrm{Aa}$ & $231,0 \mathrm{Aab}$ & $219,0 \mathrm{Aa}$ & $223,3 \mathrm{Aab}$ \\
\hline
\end{tabular}

$\mathrm{CV}=10,8 \%$

DMS Trat. $=37,70$

DMS Épocas $=34,28$

Médias seguidas pela mesma letra na linha e coluna não diferem estatisticamente entre si, pelo teste de Tukey, a 5\% de significância. Maiúscula= tratamentos; Minúscula= épocas de colheita.

os tratos culturais necessários, desde a sua implantação em outubro de 1996.

Os adubos verdes utilizados foram: feijão-de-porco (Canavalia ensiformis DC); labe-labe (Dolichus lablab L.); feijãoguandu-anão (Cajanus cajan L. Millsp) e como testemunha, braquiária brizanta (Brachiaria brizantha Hochst ex A. Rich. Stapf).

Antes da implantação dos adubos verdes, nas entrelinhas do pomar, foi realizado o controle de ácaros e da braquiária brizanta, para evitar competição com os adubos verdes. Após este manejo, em dezembro de 2003 e de 2004, efetuou-se o plantio direto destas culturas protetoras do solo, sendo aplicado $40 \mathrm{~kg} / \mathrm{ha}$ de $\mathrm{P}_{2} \mathrm{O}_{5}$ na forma de superfosfato simples. O tratamento que continha a braquiária (T4 - testemunha) foi inicialmente roçado, aplicando-se também os mesmos $40 \mathrm{~kg} / \mathrm{ha}$ de $\mathrm{P}_{2} \mathrm{O}_{5}$ na forma de superfosfato simples. Os tratamentos que continham adubos verdes: Tratamento 1-feijão-de-porco; Tratamento 2- feijão-guanduanão, e Tratamento 3-labe-labe foram semeados em 6 linhas espaçadas a $50 \mathrm{~cm}$ a partir da projeção da copa da laranjeira. A quantidade de sementes por metro linear utilizada para o feijão-de-porco, guandu-anão e labe-labe foi 3; 20 e 10, respectivamente.

Os tratamentos foram roçados e direcionados para a linha da cultura e, logo em seguida, com o auxílio de um quadrado de madeira de $1 \mathrm{~m}^{2}$, colocado aleatoriamente nas parcelas, efetuando-se o corte do material contido no quadrado. A época de corte ficou estabelecida em 120 dias após a implantação dos mesmos, de acordo com Silva et al. (1999). Foi realizada uma coleta de material fresco, sendo efetuadas quantificações das massas fresca e seca e a análise de macro e micronutrientes contidos em cada amostra, conforme a metodologia descrita por Malavolta et al. (1989). Com esses dados, estimaram-se as quantidades de matéria fresca, seca e nutrientes fornecidos à cultura.

No ano de 2003, os frutos foram colhidos em duas etapas, em virtude de duas floradas, característica comum da laranjeira 'Pêra'. No ano de 2004, houve somente uma colheita. Na colheita, foi mensurado o número e o peso total de frutos por planta $(\mathrm{kg})$ e, logo em seguida, calculados estes valores para caixas de $40,8 \mathrm{~kg}$ e também para toneladas por hectare, considerando o estande de 357 plantas/ha.

$\mathrm{O}$ rendimento de suco foi determinado após esmagamento em extratora e calculado por meio da relação massa do suco/massa do fruto e expresso em porcentagem. O "ratio" foi determinado pelo quociente entre os teores de sólidos solúveis ( ${ }^{\circ}$ Brix) e de acidez titulável (g ácido cítrico/100 g de polpa).

O delineamento experimental foi o de blocos ao acaso. A composição das parcelas foi estabelecida da seguinte forma: quatro linhas da cultura espaçadas de $7 \mathrm{~m}$, com quatro plantas por linha, espaçadas por $4 \mathrm{~m}$, ocupando $252 \mathrm{~m}^{2}$. Foram empregados quatro tratamentos, com seis repetições, totalizando 24 parcelas, onde duas plantas úteis foram utilizadas para as avaliações, e as demais funcionaram como bordadura dos tratamentos (Rossetti, 2002). Para as variáveis relativas à matéria seca dos tratamentos, produção e qualidade dos frutos, foi utilizada a análise de variância (ANOVA) de um delineamento inteiramente casualizado, com os tratamentos no esquema fatorial (Época e Adubos verdes). Todas as comparações de médias foram realizadas pelo teste de Tukey, ao nível de 5\% de significância (Cochran \& Cox, 1957).

\section{RESULTADOS E DISCUSSÃO}

O número médio de frutos por caixa de $40,8 \mathrm{~kg}$ (Tabela 1 ) diferiu significativamente entre as diferentes épocas de colheita. Também dentro dos tratamentos, o número de frutos por caixa diferiu significativamente quando se compararam a primeira e a terceira épocas de colheita com a segunda, indicativo este que os frutos, por serem de uma safra temporã, são menores, aumentando significativamente sua quantidade por caixapeso.

O peso médio dos frutos (Tabela 2) diferiu estatisticamente entre as três diferentes épocas de colheita submetidas aos diferentes tratamentos. Para o feijão-de-porco e o labe-labe, o peso médio dos frutos diferiu significativamente na primeira e na terceira épocas de colheita, quando estas foram comparadas com a segunda. No tratamento guandu-anão, o peso médio dos frutos diferiu significativamente na primeira e na segunda épocas de colheita, embora o peso médio dos frutos tenha apresentado diferença significativa entre a primeira e a segunda épocas de colheita; quando estes foram comparados com a terceira época, não apresentaram diferença significativa, repetindo os mesmos resultados do número de frutos por caixa.

De acordo com Figueiredo (1991), a produção de laranjeira 'Pêra' é muito boa, atingindo uma média de $250 \mathrm{~kg}$ de frutos por planta. Portanto, em termos de peso médio de frutos, todos os tratamentos possibilitaram um incremento em peso quando comparados com o peso médio citado pelo referido autor.

Os resultados das Tabelas 3 e 4 demonstraram não haver diferença significativa de produtividade entre os adubos verdes utilizados quando comparados com a testemunha, nos anos de 2003 e 2004. A utilização dos adubos verdes nas entrelinhas de laranjeira 'Pêra' seria uma opção interessante para os citricultores, não somente por possíveis incrementos em produtividade, que poderiam acarretar em função do uso desta prática por vários anos, mas também, pelos outros benefícios oriundos da sua utilização, citados por Von Osterroht (2002) e Neves et al. (1998), os quais reportam que a utilização da adubação

TABELA 2 - Médias relativas ao peso fresco de frutos em gramas, de pomar de laranjeira 'Pêra' [Citrus sinensis (L.) Osb.] submetido a diferentes adubos verdes. Botucatu-SP, 2005.

\begin{tabular}{ccccc}
\hline & \multicolumn{3}{c}{ Tratamentos } \\
\hline Época & Feijão-de-porco & Guandu-anão & Labe-labe & Braquiária \\
\hline $20-09-2003$ & $201,2 \mathrm{Aa}$ & $195,7 \mathrm{Aa}$ & $200,8 \mathrm{Aa}$ & $194,8 \mathrm{Aa}$ \\
$28-10-2003$ & $159,1 \mathrm{Ab}$ & $167,8 \mathrm{Ab}$ & $162,8 \mathrm{Ab}$ & $169,8 \mathrm{Aa}$ \\
$01-11-2004$ & $178,4 \mathrm{Aa}$ & $176,8 \mathrm{Aab}$ & $187,5 \mathrm{Aa}$ & $182,8 \mathrm{Aa}$ \\
\hline
\end{tabular}

$\mathrm{CV}=10,19 \%$

DMS Trat. $=28,22$

DMS Épocas $=25,66$

Médias seguidas pela mesma letra na linha e coluna não diferem estatisticamente entre si, pelo teste de Tukey, a 5\% de significância. Maiúscula= tratamentos; Minúscula= épocas de colheita. 
TABELA 3 - Médias relativas à produtividade em caixas de 40,8 kg/ planta, de pomar de laranjeira 'Pêra' [Citrus sinensis (L.) Osb.] submetido a diferentes adubos verdes. BotucatuSP, 2005

\begin{tabular}{ccccc}
\hline \multicolumn{5}{c}{ Tratamentos } \\
\hline Época & Feijão-de-porco & Guandu-anão & Labe-labe & Braquiária \\
\hline 2003 & $1,96 \mathrm{Aa}$ & $2,06 \mathrm{Aa}$ & $2,02 \mathrm{Aa}$ & $2,00 \mathrm{Aa}$ \\
2004 & $2,50 \mathrm{Ab}$ & $2,53 \mathrm{Ab}$ & $2,52 \mathrm{Ab}$ & $2,12 \mathrm{Aa}$ \\
\hline
\end{tabular}

Médias seguidas pela mesma letra na linha e coluna não diferem estatisticamente entre si, pelo teste de Tukey, a 5\% de significância. Maiúscula= tratamentos; Minúscula= épocas de colheita.

TABELA 4 - Médias estimadas de produtividade, considerando estande de 357 plantas/ha em t/ha, de pomar de laranjeira 'Pêra' [Citrus sinensis (L.) Osb.] submetido a diferentes adubos verdes. Botucatu-SP, 2005.

\begin{tabular}{ccccc}
\hline \multicolumn{5}{c}{ Tratamentos } \\
\hline Época & Feijão-de-porco & Guandu-anão & Labe-labe & Braquiária \\
\hline 2003 & $28,49 \mathrm{Aa}$ & $29,95 \mathrm{Aa}$ & $29,49 \mathrm{Aa}$ & $29,17 \mathrm{Aa}$ \\
2004 & $36,49 \mathrm{Ab}$ & $36,84 \mathrm{Ab}$ & $36,77 \mathrm{Ab}$ & $30,88 \mathrm{Aa}$ \\
\hline
\end{tabular}

Médias seguidas pela mesma letra na linha e coluna não diferem estatisticamente entre si, pelo teste de Tukey, a 5\% de significância. Maiúscula= tratamentos; Minúscula= épocas de colheita.

verde protege o solo contra a erosão, evita a infestação de ervas daninhas, descompacta o solo (dependendo da espécie usada) e, no caso das leguminosas, tem a vantagem de utilizar o nitrogênio da atmosfera, aumentando a disponibilidade desse elemento para as culturas.

Acredita-se que, com o decorrer dos anos de utilização dos adubos verdes, os valores de produtividade possam ser incrementados, porém tal fato não pôde ser comprovado no presente trabalho, em virtude da limitação do tempo para a realização da pesquisa.

As Tabelas 5 e 6 apresentam, respectivamente, os resultados das médias de matéria seca em porcentagem e do teor de macro e micronutrientes em dois anos, contidos nos adubos verdes e na testemunha. Na Tabela 6, observa-se haver diferença significativa entre os tratamentos, mostrando que o feijão-guandu-anão apresentou maior teor de matéria seca $(34,3 \%)$, no ano de 2003 , diferindo estatisticamente dos demais. No segundo ano (2004), o mesmo diferiu estatisticamente do feijão-de-porco e do labe-labe, porém não diferiu da braquiária. Estes resultados indicam a maior produção de biomassa no guandu-anão. Além disso, esta leguminosa possui qualidades adicionais, como maior facilidade de semeadura, tolerância a solos de baixa fertilidade e melhor relação custo/benefício. Frente ao exposto, recomendam-se outros estudos com o feijão-guandu-anão, como adubo verde a ser utilizado nas entrelinhas da laranjeira 'Pêra' enxertada em limoeiro 'Cravo'.

Com relação aos teores de nutrientes contidos nos adubos verdes e na testemunha (braquiária), observa-se que aqueles apresentam maior teor de N, Ca, B, Fe e Zn quando comparados com esta (Tabela 6), concordando com os relatos de Weber \& Passos (1991).

Aumentos de produção em áreas que utilizaram os adubos verdes, provavelmente, possam ser resultado de uma decomposição da matéria orgânica muito mais rica em nutrientes, quando comparada com o capim braquiária.

No presente trabalho, conforme os resultados apresentados na Tabela 7, não houve diferença estatística entre os tratamentos, para o "ratio". Contudo, foi observada diferença significativa para o "ratio" nas diferentes épocas de colheita. Tal fato talvez possa ser explicado pela diferença nas condições climáticas observada nos dois anos de cultivo e também pelas duas floradas ocorridas no ano de 2003, que obrigaram a realização de duas colheitas de frutos.

A Tabela 8 apresenta os resultados do rendimento de suco. Não houve diferença significativa entre os adubos verdes e a testemunha. Essa observação é bastante interessante, pois permite indicar a utilização dos adubos verdes em substituição à braquiária, sem haver comprometimento da qualidade dos frutos. O rendimento médio de suco diferiu estatisticamente entre as diferentes épocas de colheita, considerando os quatro tratamentos, provavelmente pelos mesmos motivos explicados para o "ratio". A porcentagem de suco e o "ratio" obtidos no presente trabalho conferem boas características aos frutos, pois, segundo Figueiredo (1991), o suco de laranja 'Pêra'

TABELA 5 - Médias relativas à matéria seca em porcentagem, de pomar de laranjeira 'Pêra' [Citrus sinensis (L.) Osb.] submetido a diferentes adubos verdes. Botucatu-SP, 2005.

\begin{tabular}{ccccc}
\hline & & Tratamentos & \\
\hline Época & Feijão-de-porco & Guandu-anão & Labe-labe & Braquiária \\
\hline 2003 & $25,7 \mathrm{Aa}$ & $34,3 \mathrm{Ba}$ & $21,7 \mathrm{Aa}$ & $18,6 \mathrm{Aa}$ \\
2004 & $19,8 \mathrm{Ab}$ & $32,0 \mathrm{Ba}$ & $22,9 \mathrm{Aa}$ & $27,2 \mathrm{ABb}$ \\
\hline
\end{tabular}

$\mathrm{CV}=22,2 \%$

DMS Trat. $=8,7$

DMS Épocas $=6,57$

Médias seguidas pela mesma letra na linha e coluna não diferem estatisticamente entre si, pelo teste de Tukey, a 5\% de significância. Maiúscula= tratamentos; Minúscula= épocas de colheita.

TABELA 6 - Mmédias relativas aos teores de macro e micronutrientes, de pomar de laranjeira 'Pêra' [Citrus sinensis (L.) Osb.] submetido a diferentes adubos verdes. Botucatu-SP, 2005.

\begin{tabular}{cccccccccccc}
\hline & $\mathrm{N}$ & $\mathrm{P}$ & $\mathrm{K}$ & $\mathrm{Ca}$ & $\mathrm{Mg}$ & $\mathrm{S}$ & $\mathrm{B}$ & $\mathrm{Cu}$ & $\mathrm{Fe}$ & $\mathrm{Mn}$ & $\mathrm{Zn}$ \\
\hline & & \multicolumn{2}{c}{$\mathrm{g} / \mathrm{kg}$} & & & & & & $\mathrm{mg} / \mathrm{kg}$ & \\
\hline FP & 27 & 1,9 & 8 & 13 & 6 & 2 & 26 & 7 & 289 & 33 & 25 \\
GA & 21 & 1,7 & 7 & 6 & 4 & 2 & 24 & 9 & 364 & 30 \\
LL & 22 & 2 & 8 & 12 & 6 & 2 & 33 & 8 & 625 & 53 \\
BQ & 13 & 2 & 12 & 5 & 7 & 2 & 12 & 6 & 225 & 34 & 21 \\
\hline
\end{tabular}

TABELA 7 - Médias relativas ao "ratio", de pomar de laranjeira 'Pêra' [Citrus sinensis (L.) Osb.] submetido a diferentes adubos verdes. BotucatuSP, 2005.

\begin{tabular}{ccccc}
\hline & & \multicolumn{2}{c}{ Tratamentos } & Labe-labe \\
\hline Epocas & Feijão-de-porco & Guandu-anão & $14,0 \mathrm{Aa}$ & \\
\hline $20-09-2003$ & $14,0 \mathrm{Aa}$ & $14,0 \mathrm{Aa}$ & $13,6 \mathrm{Aa}$ & $14,7 \mathrm{Aa}$ \\
$28-10-2003$ & $12,8 \mathrm{Ab}$ & $12,6 \mathrm{Ab}$ & $16,0 \mathrm{Ab}$ & $13,7 \mathrm{Aa}$ \\
$1^{\circ}-11-2004$ & $15,5 \mathrm{Ac}$ & $15,5 \mathrm{Ac}$ & $16,1 \mathrm{Ab}$ & \\
\hline
\end{tabular}

Médias seguidas pela mesma letra na linha e coluna não diferem estatisticamente entre si, pelo teste de Tukey, a $5 \%$ de significância. Maiúscula= tratamentos; Minúscula= épocas de colheita. 
TABELA 8 - Médias relativas ao rendimento de suco em porcentagem, de pomar de laranjeira 'Pêra' [Citrus sinensis (L.) Osb.] submetido a diferentes adubos verdes. Botucatu-SP, 2005.

\begin{tabular}{|c|c|c|c|c|}
\hline & \multicolumn{4}{|c|}{ Tratamentos } \\
\hline Época & Feijão-de-porco & Guandu-anão & Labe-labe & Braquiária \\
\hline $20-09-2003$ & $56,2 \mathrm{Aa}$ & $57,6 \mathrm{Aa}$ & $57,1 \mathrm{Aa}$ & $57,6 \mathrm{Aa}$ \\
\hline $28-10-2003$ & $49,6 \mathrm{Ab}$ & $50,2 \mathrm{Ab}$ & $51,1 \mathrm{Ab}$ & $50,5 \mathrm{Ab}$ \\
\hline $1^{\circ}-11-2004$ & $50,3 \mathrm{Ab}$ & $51,4 \mathrm{Ab}$ & $49,7 \mathrm{Ab}$ & $50,5 \mathrm{Ab}$ \\
\hline
\end{tabular}

$\mathrm{CV}=3,45 \% \quad$ DMS Trat. $=2,8 \quad$ DMS Épocas $=2,524$

Médias seguidas pela mesma letra na linha e coluna não diferem estatisticamente entre si, pelo teste de Tukey, a 5\% de significância. Maiúscula= tratamentos; Minúscula= épocas de colheita.

representa $52 \%$ do peso do fruto e os teores médios do "ratio" de 12,5 . Estas qualidades permitem que o destino dos frutos possa ser tanto o do mercado de fruta fresca como o da indústria de suco.

\section{CONCLUSÕES}

1. Não houve diferenças significativas entre os tratamentos com relação à produtividade das plantas e as características de qualidade dos frutos, "ratio" e rendimento de suco.

2. O feijão-guandu-anão apresentou o maior teor de matéria seca no primeiro ano de experimentação, diferindo estatisticamente dos demais tratamentos. No segundo ano, diferiu estatisticamente do feijãode-porco e do labe-labe, produzindo maior quantidade de biomassa.

\section{REFERÊNCIAS}

AMBROSANO, E. J.; MURAOKA, T.; CERVEIRA, R. Adubação verde para a agricultura orgânica. Piracicaba: Degaspari, 2000. p. 17-76.

COCHRAN, W. E.; COX, E. M. Experimental designs. $2^{\text {nd }}$ ed. New York: John Wiley \& Sons, 1957. 611p.

DEMATTÊ, J. L.; VITTI, G. C. Alguns aspectos relacionados ao manejo de solos para os citros. In: SEMINÁRIO INTERNACIONAL DE CITROS, 2., 1992, Bebedouro. Anais... Campinas: FUNDAÇÃO CARGILL, 1992.p. 69-99.

EMBRAPA. Sistema Brasileiro de Classificação de Solos. Brasília:EMBRAPA, 1999. $412 \mathrm{p}$.

FIGUEIREDO, J. O. Variedades-copa de valor comercial. In: RODRIGUEZ, O.; VIÉGAS. F.; POMPEU JÚNIOR, J.; AMARO, A.A. (Ed.). Citricultura brasileira. Campinas: Fundação Cargill, 1991. v.1, p.228-64.
MALAVOLTA, E.; VITTI, G. C.; OLIVEIRA, S. A. Avaliação do estado nutricional das plantas: princípios e aplicações. Piracicaba: Editora Potafos, 1989.201p.

MELARATO, M. S. A cobertura vegetal do solo na citricultura. In: SEMINÁRIO INTERNACIONAL DE CITROS, 5., 1998, Bebedouro. Anais... Bebedouro: Fundação Cargill, 1998. p. 203220.

MELLO, M. H. de A.; PEDRO JR, M. J.; LOMBARDI NETO, F. Hidrologia, climatologia e agrometeorologia. In: BERTOLINI, D. et al. Potencialidades agrícolas das terras do Estado de São Paulo. Campinas: CATI, 1994. p. 1-69.

NEVES, C. S. V. J. et al. Influência de sistemas de manejo de solo em pomar de tangerinas Ponkan sobre limão Cravo em um latossolo roxo. Revista Brasileira de Fruticultura, Cruz das Almas, v. 20, n. 3, p. 367-374, 1998 .

ROSSETTI, A. G. Influência da área da parcela e do número de repetições na precisão de experimentos com arbóreas. Pesquisa Agropecuária Brasileira, Brasília, DF, v. 37, n. 4, p. 433-438, 2002.

SILVA, J.A. A.; DONADIO, L. C.; CARLOS, J. A. D. Adubação verde em citros. Jaboticabal: Funep, 1999. 37p.

VON OSTERROHT, M. O que é uma adubação verde: princípios e ações. Agroecologia Hoje, Botucatu, n. 14, p. 9-11, maio/jun 2002.

WEBER, O. B.; PASSOS, O. S. Adubação verde: aspectos relacionados à citricultura. Revista Brasileira de Fruticultura, Cruz das Almas, v. 13, n. 4, p. 295-303, out. 1991. 